\title{
Actividades hidrolíticas y caracterización isoenzimática de poblaciones microbianas aisladas del patrimonio documental del Archivo General de Colombia
}

\author{
Luz Stella Villalba MSc. ${ }^{1}$, José Fernando Mikán Ph.D² y Jimena Sánchez MSc. ${ }^{3}$ \\ ${ }^{1}$ Laboratorio de análisis y control, Archivo de Bogotá - ${ }^{2}$ Facultad de Medicina, Universidad Militar Nueva Granada $-{ }^{3}$ Departamento \\ de biología, Universidad Nacional de Colombia \\ Recibido:08-06-2004 Aceptado:29-09-2004
}

\begin{abstract}
Resumen
Este trabajo presenta un modelo para el aislamiento y evaluación de microorganismos agentes deteriorantes del acervo documental. Se recuperaron e identificaron 28 aislamientos tanto de las unidades de conservación con biodeterioro como de la atmósfera del depósito 15 del Archivo General de la Nación de Colombia (AGN). De este grupo, 16 aislamientos microbianos mostraron capacidad hidrolítica sobre fibras vegetales cuando se cultivaron en medios con paredes celulares al 1\% como única fuente de carbono. A las poblaciones microbianas recuperadas se les evaluó su capacidad para hidrolizar celulosa, xilano, almidón y proteínas, considerando los halos de degradación y el número de sustratos hidrolizados, se seleccionaron cuatro aislamientos: dos de Penicillium sp., uno de Bacillus sp. y uno de Actinopolyspora sp. A los aislamientos se les cuantificó las actividades depolimerasas y accesorias y se les determinó el perfil isoenzimático para celulasas y xilanasas. Los resultados sugieren: (i) los hongos filamentosos y actinomycetes son más eficientes en la degradación de polímeros complejos, (ii) posiblemente las poblaciones bacterianas actúan como colonizadores secundarios y (iii) el perfil isoenzimático permite descartar microorganismos saprófitos, de especializados en degradar soporte celulolítico.
\end{abstract}

Palabras claves: biodeterioro, poblaciones microbianas, hidrólisis, isoenzimas, acervo documental, polímero complejo.

\begin{abstract}
Hydrolytic activity and isoenzymatic characterization of microbial population Isolated of documental Heritage of General Archive of Colombia (AGN).

This work shows an isolation and evaluation model of microorganisms deterioration agents of documental heritage. 28 Isolations were recovered and identified as conservation with biodeterioration as in deposit No. 15 atmosphere of AGN (Bogotá-Colombia). Of this group, 16 microbial isolations showed hydrolytic capability on vegetable fibers when they were cultivated in with cellular walls at $1 \%$ as the unique carbon source. In the recovered microbial populations were evaluated the capability to hydrolyze cellulose, xylane, almidon and
\end{abstract}


protein. Taking into account degradation haloes and the number of hydrolyzed substrates were selected four isolations: two of Penicillium sp., one of Bacillus sp. and one of Actinopolyspora sp.. Polymerase activities and accessories were quantified on them and it was determined Isoenzymatic profile to cellulase and xilanase. The results suggest: filamentous fungi and Actinomycete are more efficient degradation complex polymer (cellulose), probably the bacterial population acts as a secondary settler and Isoenzymatic profile permits discard saprophyte microorganisms, specialized in degrading cellulolytic support.

Key Words: biodeterioration, microbial population, enzymatic hydrolytic, Isoenzyme.

\section{Introducción}

El acervo documental considerado de interés nacional, custodiado en archivos o museos, está expuesto permanentemente a sufrir alteraciones físicas, químicas y/o biológicas. Los deterioros biológicos, causados por los microorganismos como consecuencia de colonizaciones puntuales y de la utilización del papel como fuente de carbono y energía, ocasionan cambios no deseados en las propiedades del material. En la colonización y degradación del soporte papel,

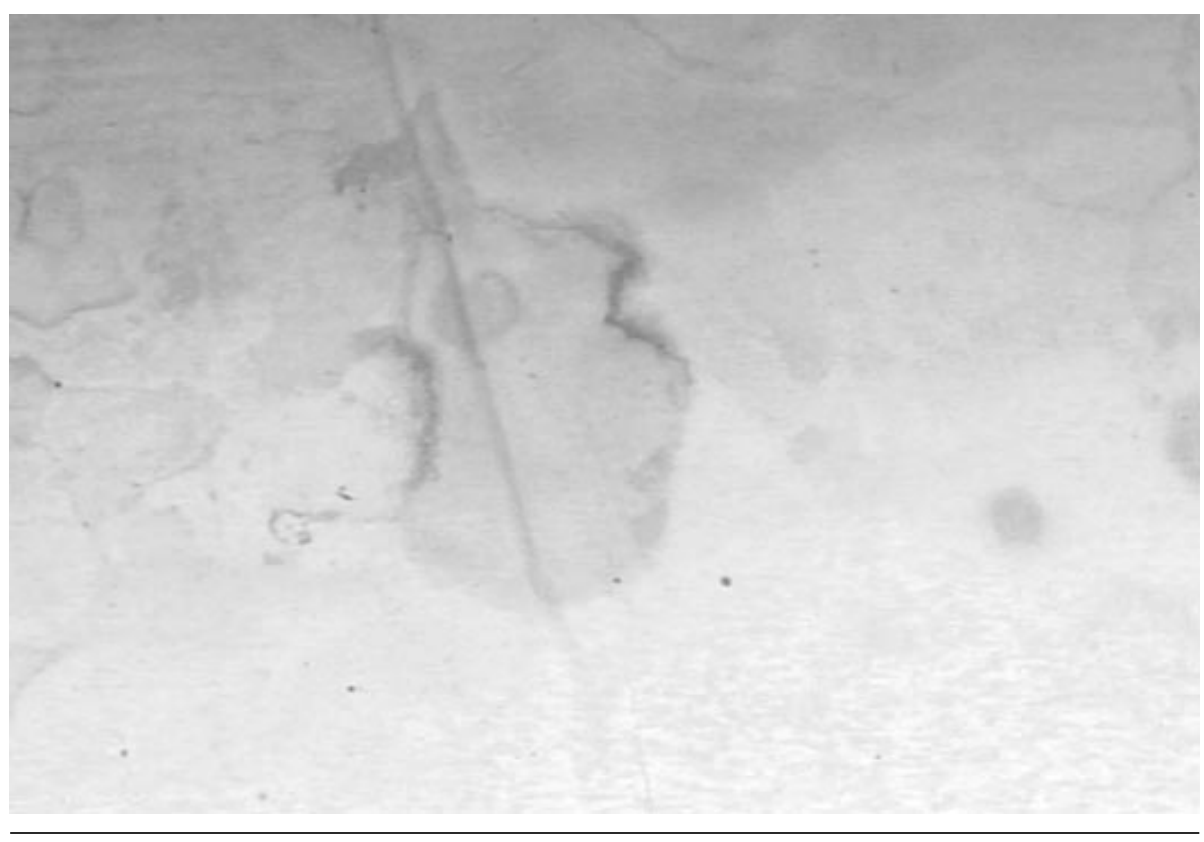

Figura 1. Indicadores de biodeterioro documental. interactúan las diferentes poblaciones microbianas, bacterias, hongos y actinomycetes, el papel compuesto de fibras vegetales, aditivos funcionales (encolantes, carga, abrillantadores ópticos, agentes consolidantes) y tintas con aglutinantes orgánicos, es vulnerable a factores abióticos y bióticos. Los microorganismos, principales agentes bióticos utilizan el papel como fuente nutricional, haciendo uso de sus complejos sistemas enzimáticos (glucanasas y proteasas), ayudados por las condiciones micro y macroclimáticas del ambiente.

Esta investigación evaluó el compromiso de las diferentes poblaciones de microorganismos (bacterias, hongos y actinomycetes) en la degradación del material, estudiando sus actividades hidrolíticas y perfil isoenzimático. Para ello, se recuperaron e identificaron las diferentes poblaciones microbianas cultivables a partir de la atmósfera y de las unidades de conservación con biodeterioro, se evaluó la capacidad hidrolítica de los microorganismos, se caracterizó parcialmente los complejos isoenzimáticos por isoelectroenfoque (IEF) y se analizó la relación entre los microorganismos estudiados y su acción hidrolítica, como factores determinantes en el proceso de biodeterioro de la documentación.

\section{Materiales y métodos}

1. Recuperación microbiana: se seleccionaron áreas representativas del depósito y en estos puntos 
se realizó el muestreo ambiental por el método de sedimentación sobre agar y se tomaron mediciones de temperatura y humedad relativa. El muestreo se realizó por triplicado a intervalos de un mes, por un periodo de tres meses. La muestra documental, 90 legajos encuadernados, se seleccionaron aleatoriamente del total de población afectada correspondiente 256 legajos. Las muestras tomadas por hisopado, según los indicadores de deterioro (Figura 1), se incubaron en un caldo de recuperación (1). Alícuotas de $0.1 \mathrm{ml}$ del caldo se sembraron simultáneamente en placas de agar en medios primarios y en medios sólidos y líquidos con pared celular vegetal al 1\% como única fuente de carbono, la cual se preparó siguiendo el procedimiento descrito por Cooper et al., 1988. La identificación se llevó acabo por microbiología tradicional y pruebas rápidas, como el BBL Crystal.

2. Evaluación y selección preliminar de las cepas con actividades hidrolíticas: los aislamientos de los documentos y de la atmósfera del depósito, se inocularon en medios de cultivo sólidos conteniendo como fuente única de carbono los siguientes sustratos al $1 \%(\mathrm{p} / \mathrm{v})$ disueltos en solución de minerales y agar $(1.5 \% \mathrm{p} / \mathrm{v})$ : carboximetil celulosa (CMC), xilano de hojuelas de avena (XIL), pectina de manzana (PEC), almidón (AL) y gelatina nutritiva. La inoculación se realizó siguiendo la metodología descrita por Mikán y Castellanos (2004). Los halos de degradación se evidenciaron adicionando como revelantes: rojo congo al $1 \%(\mathrm{p} / \mathrm{v})$ para celulosa y xilano, rojo de rutenio al $0.2 \%(\mathrm{p} / \mathrm{v})$ para pectina, lugol para almidón y por licuefacción de la gelatina para evaluar actividad proteolítica (2).

Se midió el diámetro de las colonias y el de los halos, producto de la degradación enzimática, de acuerdo a la formula: $\mathrm{A}-\mathrm{B}=\mathrm{C}$; donde $\mathrm{A}$ es el diámetro de la colonia mas el halo de hidrólisis, $\mathrm{B}$ es el diámetro de la colonia y $\mathrm{C}$ es el resultado de la diferencia de las dos medidas. Se seleccionaron los microorganismos de acuerdo al diámetro del halo y al número de sustratos degradados.

\section{Cuantificación de las actividades hidroliticas:} los microorganismos seleccionados se cultivaron en medios líquidos CMC, PEC y XYL al 1\% (p/v) con agitación (150rpm). Cada aislamiento contó con tres frascos por cada uno de los 5 intervalos de tiempo $(0,72,96$, $120,168 \mathrm{~h}$ ) para hongos y actinomycetes y 10 intervalos para bacterias no filamentosas (cada 12 horas). Alícuotas de 100ul de los sobrenadantes se congelaron $\mathrm{a}-20^{\circ} \mathrm{C}$, para luego cuantificar el contenido de proteínas y las actividades celulolíticas, xilanolíticas y pectinolíticas $(3,4)$.

Las actividades accesorias acetil-esterasa, arabinofuranosidasa, xilosidasa y galactosidasa fueron determinadas por la liberación del p-nitrofenol, de los respectivos sustratos p-nitrofenil derivados $(405 \mathrm{~nm})$, disueltos en buffer acetato de sodio $50 \mathrm{mM}$, pH 5,5, utilizando una curva de p-nitrofenol en el rango de 0-5 ìmoles, con la que se convirtió la absorbancia a actividad en nanokatales $/ \mathrm{ml}$.

\section{Isoelectroenfoque y zimogramas: se prepara-} ron geles de IEF para analizar el perfil isoenzimático, punto isoeléctrico de los polipéptidos, en los sobrenadantes con actividades enzimáticas empleando marcadores de pI (Ampholine pH de 3 a 10, Pharmacia-Biotech) y tinciones específicas. Medios de cultivo concentrados, resuspendidos en 5 a $10 \mathrm{ml}$ de agua desionizada se corrieron en geles de poliacrilamida de $125 \times 105 \times 0.4 \mathrm{~mm}$ en un aparato de electroforesis horizontal (LKB Bromma 2117 Multiphor, Pharmacia), el cual fue conectado a un sistema refrigerante a $6^{\circ} \mathrm{C}$ (MultiTem III, Pharmacia).

Las condiciones de corrido fueron: (i) precorrido a $1000 \mathrm{~V}, 12 \mathrm{~mA}, 12 \mathrm{~W}$ por $30 \mathrm{~min}$; (ii) aplicación de muestras (1 a 10ml); (iii) corrido 1 a $2200 \mathrm{~V}, 12 \mathrm{~mA}, 11 \mathrm{~W}$ por 45min; (iv) remoción de papeles de siembra; (v) corrido 2 a $2400 \mathrm{~V}, 10 \mathrm{~mA}, 10 \mathrm{~W}$ por $45 \mathrm{~min}$ y (vi) focalización a $3000 \mathrm{~V}, 10 \mathrm{~mA}, 10 \mathrm{~W}$ por $30 \mathrm{~min}$; usando como electrolitos $\mathrm{NaOH} 1 \mathrm{M}$ y $\mathrm{H}_{3} \mathrm{PO}_{4} 1 \mathrm{M}$. La actividad celulolítica y xilanolítica fue detectada siguiendo el método de Mackenzie \& Williams (1984). 


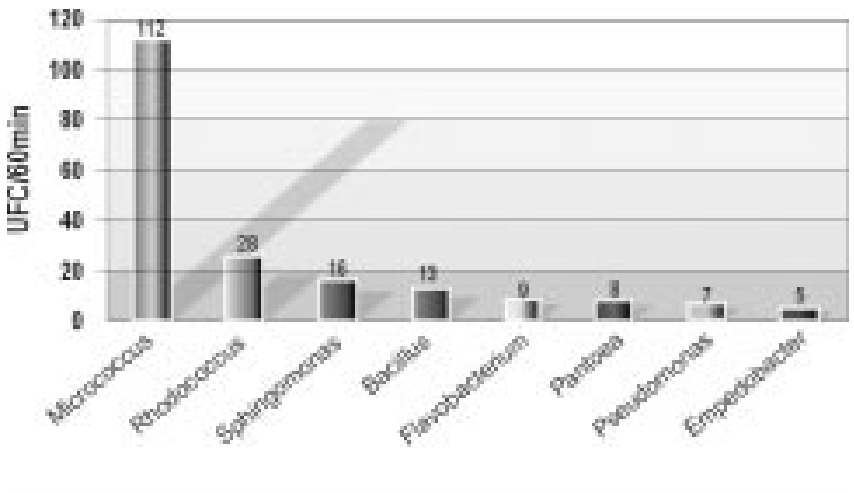

Figura 2. Frecuencia de géneros bacterianos recuperados del depósito 15 del AGN (Archivo General de la Nación)

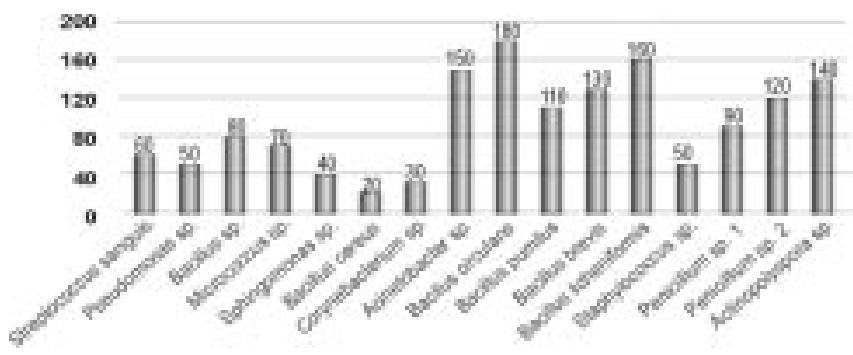

Figura 3. Frecuencia de géneros de microorganismos aislados de las unidades de conservación evaluadas

\section{Resultados}

En condiciones de temperatura y humedad relativa entre $18.8^{\circ} \mathrm{C}-20^{\circ} \mathrm{C}$ y $54.1 \%-56.5 \%$ respectivamente, se recuperaron e identificaron 12 cepas bacterianas. El género con mayor frecuencia fue Micrococcus $s p$. (112 UFC/60min), seguido de Rhodococcus sp. (26 UFC /60 min) y Sphingomonas sp. (16 UFC/ $60 \mathrm{~min}$ ) (Figura 2).

De las unidades de conservación se recuperaron 16 aislamientos, el género Bacillus presentó el mayor recuento $(680 \mathrm{UFC} / \mathrm{ml})$, con 6 especies, las representativas circulans y licheniformis, con 180 $\mathrm{UFC} / \mathrm{ml}$ y $160 \mathrm{UFC} / \mathrm{ml}$ respectivamente (Figura 3 ).

Se recuperaron dos aislamientos de Penicillium sp., género que está entre los grupos más prolíficos y ubicuos de hongos y cuyas enzimas han sido muy estudiadas por su actividad ecológica en la descomposición de materiales orgánicos como el papel, la madera y textiles, entre otros. De las poblaciones recuperadas de la documentación, es de gran importancia
Tabla 1. Diámetros de los halos de degradación $(\mathrm{cm})$ de las cepas bacterianas en xilano y $\mathrm{CMC}$ al $1 \%$. Se muestra el promedio de tres replicas \pm D.S

\begin{tabular}{|c|c|c|c|}
\hline \multicolumn{2}{|r|}{ Bacterias } & \multicolumn{2}{|c|}{$\begin{array}{l}\text { Halos de } \\
\text { degradación }(\mathrm{cm})\end{array}$} \\
\hline \multirow{3}{*}{ Celulosa } & Bacilles up.1 & 0.4 & \pm 0.1 \\
\hline & Bacillus cereus 1 & 0.4 & \pm 0.1 \\
\hline & Bacillus ciroulans & 0.4 & \pm 0.1 \\
\hline \multirow{3}{*}{ Xilano } & Bacilus sp. 1 & 0.4 & \pm 0.1 \\
\hline & $\begin{array}{c}\text { Pantoea } \\
\text { agglomerans }\end{array}$ & 0.2 & \pm 0.1 \\
\hline & Psendiomonas sp. 1 & 0,2 & \pm 0.2 \\
\hline
\end{tabular}

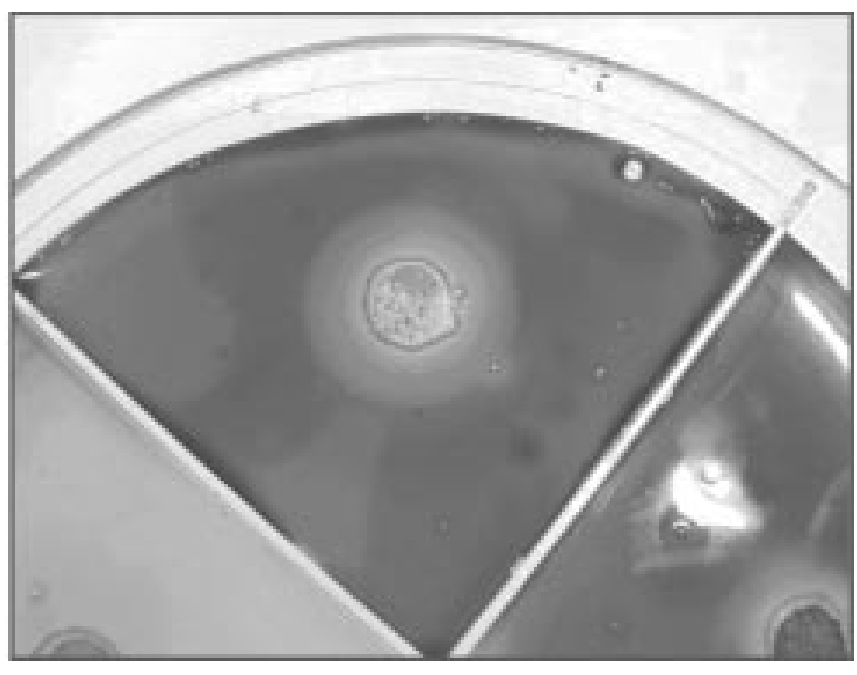

Figura 4. Halos de degradación de los hongos filamentosos en los sustratos CMC y Xilano al 1\%

Actinopolyspora sp., con uno de los mayores recuentos, $140 \mathrm{UFC} / \mathrm{ml}$.

Selección y detección de la actividad hidrolítica de los microorganismos: la evaluación semicuantitativa de las actividades hidrolíticas de las cepas bacterianas mostró que el $25 \%$ degrado alguno de los polímeros y que ninguna tuvo acción hidrolítica frente a pectina (Tabla 1).

Los hongos filamentosos y el actinomycete mostraron halos de hidrólisis en los tres sustratos evaluados (Figura 4). Los primeros no presentaron diferencias significativas al comparar sus diámetros de hidrólisis en CMC y XIL $(5,6)$. Sin embargo, este grupo mostró halos significativamente mayores que Actinopolyspora sp. (Tabla 2).

Así mismo, se detectó actividad amilolítica en el $67.8 \%$ de los microorganismos recuperados y los 
Tabla 2. Diámetros de los halos de degradación (cm) de los hongos filamentoso y Actinopolyspora sp. en xilano, CMC y pectina al $1 \%$. Se muestra el promedio de tres replicas \pm D.S

\begin{tabular}{|c|c|c|c|}
\hline \multicolumn{2}{|c|}{ Mieroorganismo } & \multicolumn{2}{|c|}{ Hales de degradación (cm) } \\
\hline \multirow{2}{*}{ Celulosa } & Penicinhum ap 1 & 0.7 & $\pm 0,1$ \\
\hline & $\begin{array}{c}\text { Panicidium sp } 2 \\
\text { Actinopolysspara sp }\end{array}$ & 0,9 & $\begin{array}{l}10.1 \\
+0.1\end{array}$ \\
\hline \multirow{3}{*}{ Xilano } & Penjedilum sp.1 & 1.7 & $\pm 0,1$ \\
\hline & Ponicillum sp.2 & 1,9 & \pm 0.3 \\
\hline & Actinopalyspora sp. & 0,4 & \pm 0.1 \\
\hline \multirow{3}{*}{ Pectina } & Peniedilum sp. 1 & 0.8 & $\pm 0,1$ \\
\hline & Penicillium op 2 & 1.1 & \pm 0.3 \\
\hline & Actinopolysspora sp & 0.6 & +0.1 \\
\hline
\end{tabular}

aislamientos de Bacillus presentaron los mayores halos de degradación $(1.8-2.5 \mathrm{~cm})$, seguidos por los aislamientos de Micrococcus sp. Penicillium sp. y Actinopolyspora sp..

Respecto de la actividad proteolítica, los géneros representativos fueron Bacillus sp., Micrococcus sp., Penicillium sp. y Actinopolyspora sp. El análisis de la actividad amilolítica y proteolítica de los microorga-
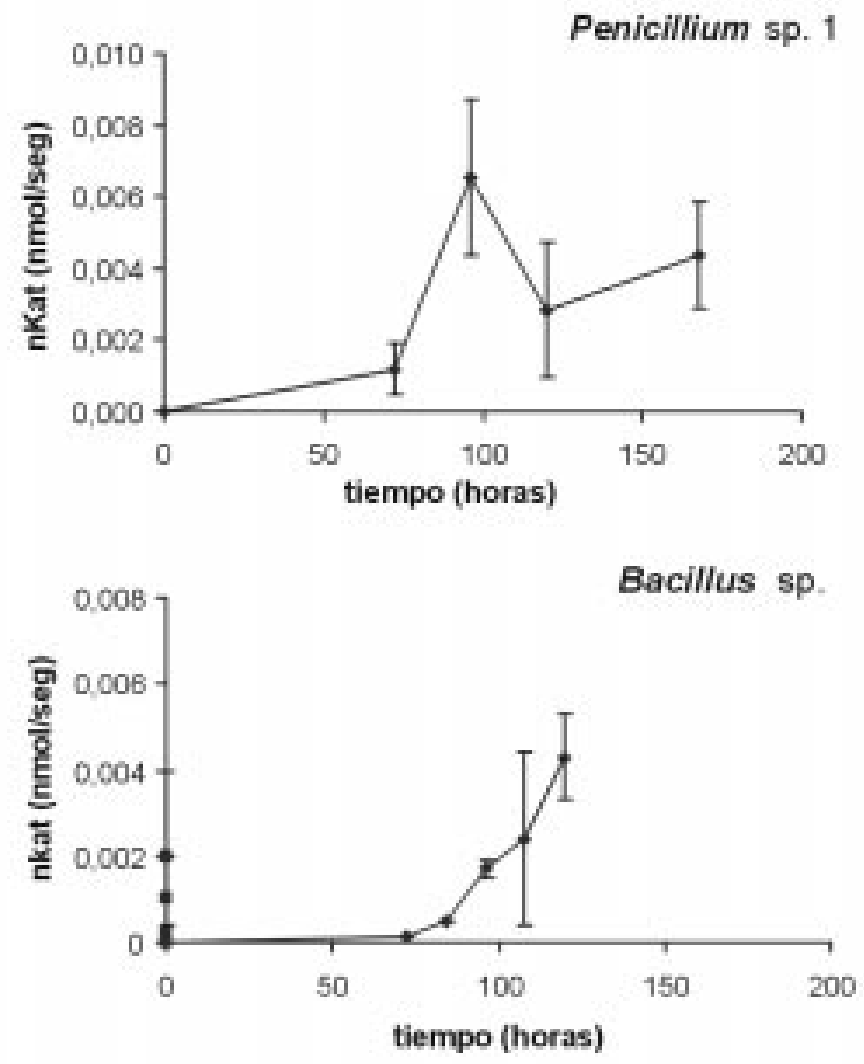

nismos, indica que los asilamientos de Bacillus, Penicillium y Actinopolyspora (Tabla 2). De acuerdo a la actividad hidrolítica, se seleccionaron 4 microorganismos: aislamientos No 1 y No 2 de Penicillium, Bacillus sp. y Actinopolyspora sp., considerando: (i) su capacidad de degradar más de 3 sustratos y (ii) halos superiores o iguales a $0.4 \mathrm{~cm}$.

Cuantificación de las actividades enzimáticas de los microorganismos: los dos aislamientos de Penicillium y Actinopolyspora sp. mostraron mayor eficiencia en degradar celulosa y xilano (Figuras 5 y 6 ) y actividades enzimaticas accesorias; arabinofuranosidasa, xilosidasa y acetil-esterasa, para la degradación completa de los polímeros.

Tanto el aislamiento No 1 de Penicillium sp. como el de Actinopolyspora sp., mostraron un aumento progresivo de la actividad pectinasa durante el tiempo evaluado, correlacionado con altas actividades arabinofuranosidasa
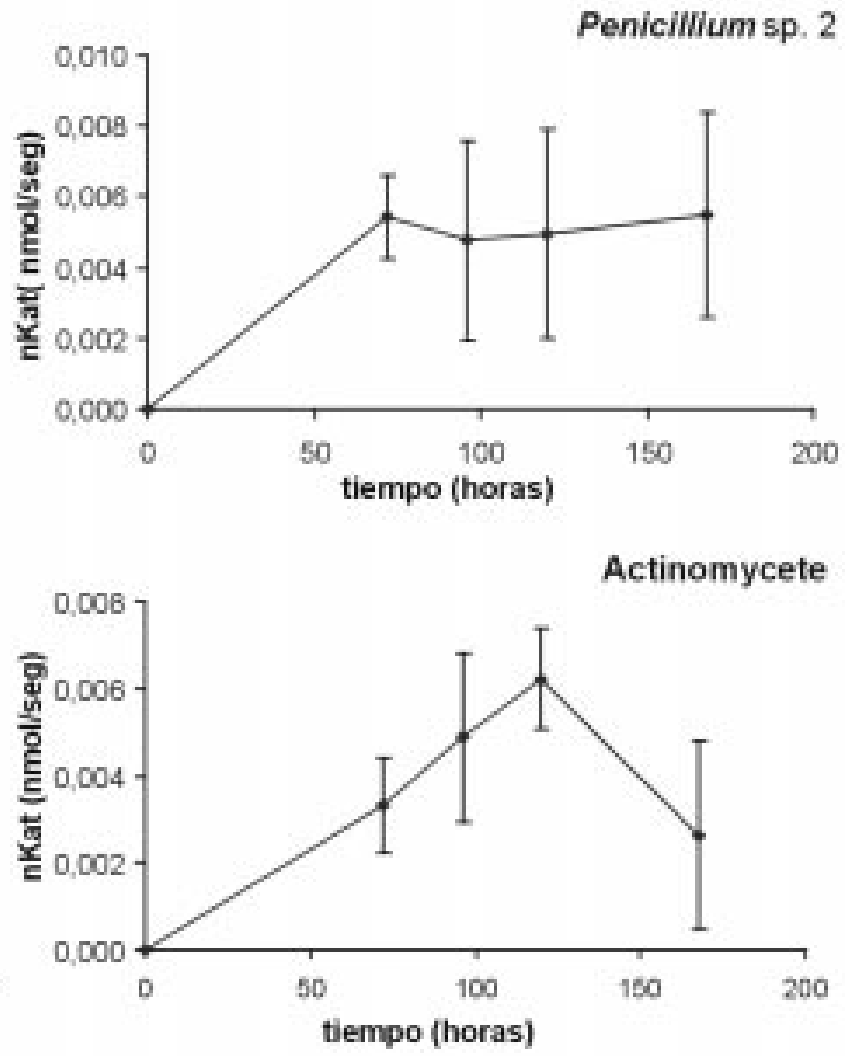

Figura 5. Actividad celulasa: Penicillium sp.1, Penicillium sp.2, Actinopolyspora sp. y Bacillus sp.1 en nano moles de azúcares reductores liberados por segundo por $\mathrm{ml}$ (nKats/ml), durante el período evaluado. Las barras muestran la desviación estándar del promedio de tres replicas. 

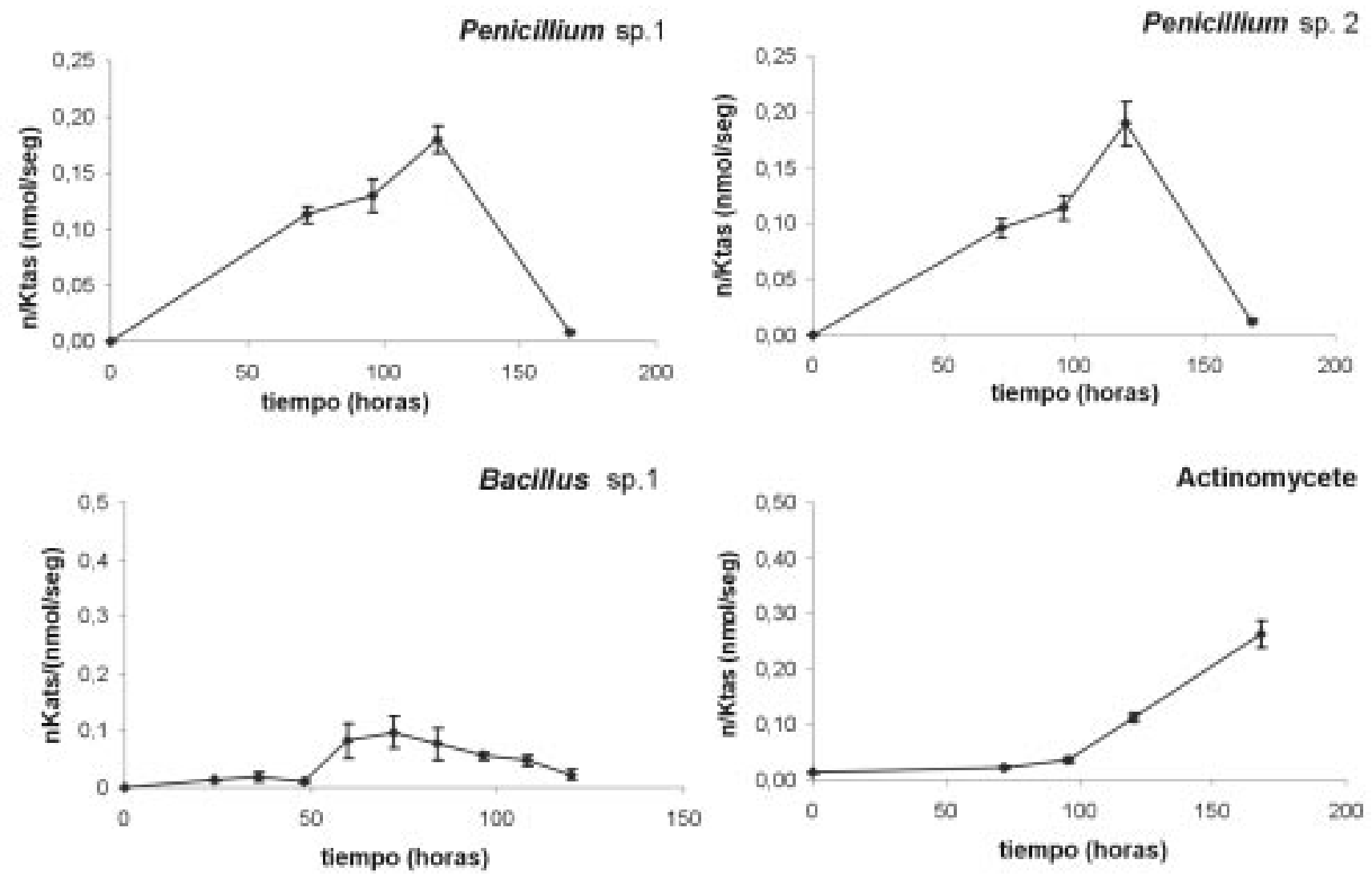

Figura 6. Actividad xilanasa para los microorganismos en nano moles de azúcares reductores liberados por segundo por $\mathrm{ml}$ (nKats/ml), durante el periodo evaluado. Las barras muestran la desviación estándar del promedio de tres replicas.

y galactosidasa, accesorias para la degradación completa de pectatos. Lo anterior puede sugerir que estos microorganismos, además de utilizar la celulosa, pueden degradar otros compuestos como la goma arábiga utilizada como encolante, la cual al hidrolizarse produce arabinosa, galactosa, ramnosa y ácido glucurónico, utilizados como fuente de carbono y energía.

Análisis de Isoelectroenfoque y determinación de isoenzimas con actividad celulolitica y xilanolítica: los resultados del zimograma para celulasas (Figura $7 \mathrm{y}$ Tabla 3), muestran que Penicillium (aislamiento No.2), cuenta con un mayor número de isoformas (4). En contraste, el aislamiento No.1 mostró solo una banda con pI 4.65. En las bacterias se detectaron 2 isoformas con $\mathrm{pI}$ ácido.

El zimograma para xilanasas (Figura 8 y Tabla 4) muestra que el aislamiento No 2 de Penicillium produjo el mayor número de bandas (5) distribuidas en todo el rango de $\mathrm{pH}$. En contraste, el aislamiento No.1 mostró 2 isoformas.

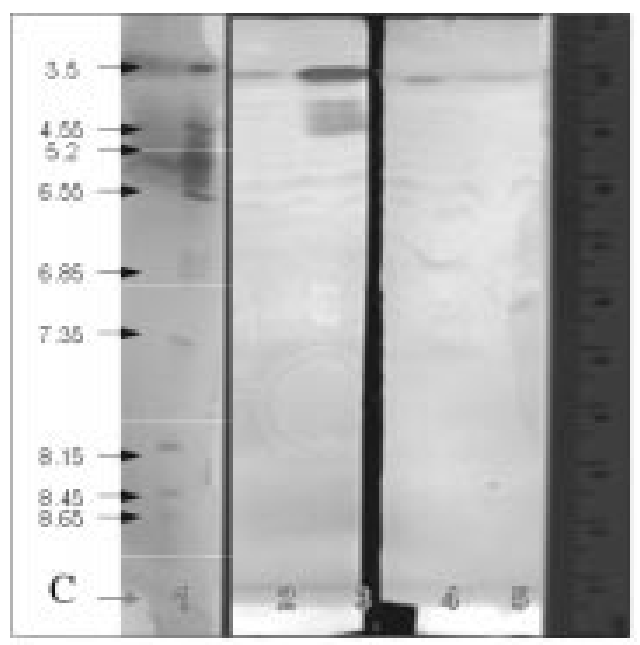

Figura 7. Zimograma para actividad celulolítica: 1.Patrones, 2 Actinopolyspora sp. 3. Bacillus sp 4. Penicillium sp. 15. Penicillium sp 
Tabla 3. Valores de pl de isoenzimas con actividad celulolítica, obtenidas por interpolación en la ecuación de la recta que correlaciona las distancias desde el cátodo $(\mathrm{mm})$ y los valores de $\mathrm{pl}$ de los marcadores.

\begin{tabular}{|c|c|c|}
\hline Microorganismo & $\begin{array}{c}\text { Distancia } \\
(\mathrm{mm})\end{array}$ & pl \\
\hline Actinopolyspora sp. & 60 & 6,53 \\
& 90 & 4,71 \\
\hline \multirow{2}{*}{ Bacillus sp. 1 } & 51 & 7,07 \\
\hline Penicillium sp. 1 & 91 & 4,65 \\
\hline \multirow{2}{*}{ Penicillium sp. 2 } & 81 & 4,65 \\
\hline & 86 & 5,20 \\
& 92 & 4,08 \\
& & 9,59 \\
\hline
\end{tabular}

\section{Discusión}

Los parametros ambientales de temperatura y humedad relativa para el depósito donde se realizó el estudio permanecieron entre $18.8^{\circ} \mathrm{C}-20^{\circ} \mathrm{C}$ y $54.1 \%$ $-56.5 \%$ respectivamente. Los valores anteriores están dentro del rango sugerido para las condiciones climáticas en archivos (7). El género Bacillus presentó el mayor recuento y podría participar en el deterioro del papel, por la acción de sus enzimas celulasas y xilanasas. La mayoría de las especies descritas hidrolizan el almidón, el cual es utilizado como encolante en la fabricación del papel produciendo ácidos, los cuales con el tiempo aceleran el deterioro de la fibra celulósica (8).

Es importante destacar la presencia de los géneros Streptococcus sp. y Staphylococcus sp., por estar asociados principalmente con la piel y mucosas humanas, indicando inadecuada manipulación de los documentos.

Así mismo, se recuperaron dos aislamientos de Penicillium sp., género que está entre los grupos más prolíficos y ubicuos de hongos y cuyas enzimas han sido muy estudiadas por su actividad ecológica en la descomposición de materiales orgánicos como el papel, la madera y textiles, entre otros.

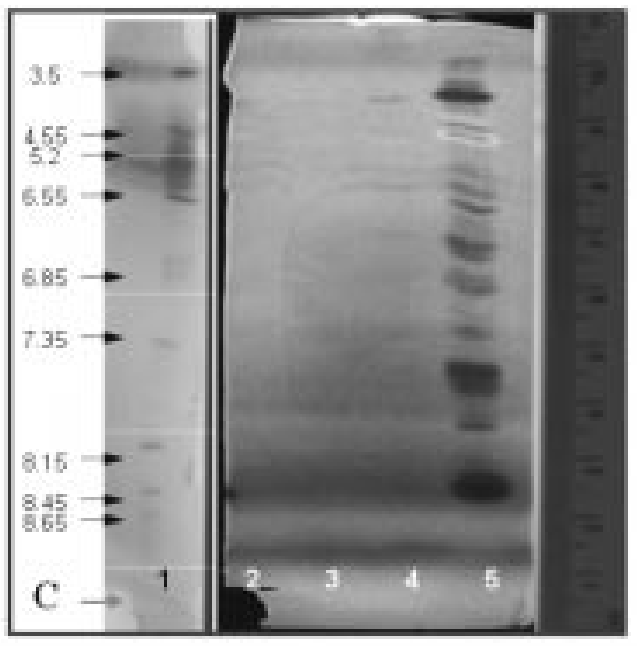

Figura 8. Zimograma para actividad xilanolítica 1.Patrones, 2 Actinopolyspora sp. 3. Bacillus sp 4. Penicillium sp.1 5.Penicillium sp.2.

De las poblaciones recuperadas de la documentación, es de gran importancia Actinopolyspora sp., por su conocida participación en el biodeterioro del papel dada su habilidad para penetrar los soportes, por la excreción de enzimas como amilasas, quitinasas, arabinasas, lipasas, proteasas, celulasas y hemicelulasas y por la producción de pigmentos (9).

Lo anterior corroboraría lo reportado en la literatura, donde los hongos tienen una mayor capacidad hidrolítica para degradar sustratos celulósicos. De acuerdo a los resultados obtenidos, los aislamientos de Penicillium sp. evaluados, fueron capaces de producir celulasas y hemicelulasas, en concordancia con lo reportado donde se destaca la importancia de los mismos, como factores bióticos importantes en el deterioro del papel (10-11).

Respecto de la actividad proteolítica, los géneros representativos fueron Bacillus sp., Micrococcus sp., Penicillium sp. y Actinopolyspora sp. El análisis de la actividad amilolítica y proteolítica de los microorganismos indica que los asilamientos de Bacillus, Penicillium y Actinopolyspora, por su conocido rol ecológico, pueden degradar el material fibroso y no fibroso del papel (Tabla 2), gracias a sus complejos sistemas enzimáticos.

Correspondencia: revistanova@unicolmayor.edu.co 


\begin{tabular}{|c|c|c|}
\hline Microorganismo & $\begin{array}{c}\text { Distancia } \\
\text { (mm) }\end{array}$ & pl \\
\hline \multirow{2}{*}{ Actinomycete } & 17 & 9,13 \\
\hline & 88 & 4,83 \\
\hline Bacillus sp. 1 & 87 & 4,89 \\
\hline \multirow{2}{*}{ Penicillium sp. 1} & 63 & 6,35 \\
\hline & 89 & 4,77 \\
\hline \multirow{18}{*}{ Penicillium sp. 2} & 13 & 9,37 \\
\hline & 27 & 8,52 \\
\hline & 35 & 8,04 \\
\hline & 38 & 7,86 \\
\hline & 46 & 7,38 \\
\hline & 48 & 7,25 \\
\hline & 53 & 6,95 \\
\hline & 55 & 6.83 \\
\hline & 58 & 6,65 \\
\hline & 60 & 6,53 \\
\hline & 69 & 5,98 \\
\hline & 72 & 5,80 \\
\hline & 75 & 5,62 \\
\hline & 81 & 5,26 \\
\hline & 83 & 5,14 \\
\hline & 90 & 4,71 \\
\hline & 92 & 4,59 \\
\hline & 95 & 4,41 \\
\hline
\end{tabular}

Tabla 4. Valores de pl de isoenzimas con actividad xilanolítica, obtenidas por interpolación en la ecuación de la recta que correlaciona las distancias desde el cátodo (en $\mathrm{mm}$ ) y los valores de pl de los marcadores.

En cuanto a la cuantificación de las actividades enzimáticas de los microorganismos, los dos aislamientos de Penicillium y Actinopolyspora sp. mostraron mayor eficiencia en degradar celulosa y xilano; indicando que los microorganismos mencionados poseen las enzimas necesarias para la degradación eficiente de los polímeros que hacen parte del material fibroso del papel.

Los resultados del zimograma para celulasas mostraron que estas degradan mas eficientemente en condiciones ácidas, dando a los microorganismos un nivel de especialización en la degradación de complejos celulósicos como es el caso del papel $(4,8)$. De igual forma, estas características sugerirían mecanismos de protección de las enzimas celulolíticas para soportar condiciones ácidas, pues durante los procesos de degradación del papel por los consorcios o biopelículas de microorganismos producen ácidos orgánicos, los cuales de otra manera producirían denaturación de las enzimas.

El zimograma para xilanasas muestra que el aislamiento de Penicillium produjo el mayor número de bandas, en contraste, el aislamiento No.1 que mostró 2 isoformas. Lo anterior sugeriría una posible especialización en la degradación de papel del aislamiento No 1, al presentar solo una isoforma celulolítica y dos xilanolíticas, a diferencia del otro aislamiento, que parece conservar características saprofíticas, relacionadas con la expresión de una cantidad de isoformas de diferente $\mathrm{pI}$, concordante con la necesidad para adaptarse y colonizar en diferentes materiales lignocelulósicos (12-13).

Finalmente, el daño del material documental puede ser el resultado de una sucesión ecológica de microorganismos que en conjunto, biofilms o consorcios, potencializan el deterioro de la documentación. La participación de los microorganismos en los procesos de biodeterioro del papel esta dada en función de la composición química del material (fibroso y no fibroso), de los sistemas multienzimáticos eficientes del microorganismo para utilizar las diferentes fuentes nutricionales y de las condiciones ambientales.

El conocimiento de la microflora que participa en la degradación del soporte, facilita tomar medidas higiénico-sanitarias y permite explorar posibles potenciales de los microorganismos

\section{Referencias}

1. Cooper RM, Longman D, Campbell A, Henry M, Lees PE. Enzymatic adaptation of cereal pathogens to the monocotyledonous primary wall. Physiological and Molecular. Plant Pathology 1988; 32: 33-47.

2. Galiotou P, Kapantai M, Kalantzi O. Growth conditions of Aspergillus sp. ATHUM.3488 for polygalacturonase production. Applied Microbiology and Biotechnology 1997; 47: 425-9.

3. Somogy M. Notes on sugar determination. Journal of biological chemistry $1951 ; 160: 61-7$. 
4. Lynd L., Weimer PI, Van Zyl W, Pretorius I. Microbial cellulose utilization: fundamentals and biotechnology. Microbiology and Molecular Biology. Reviews 2002; 66 (3): 506-77.

5. Mackenzie CR, Williams RE. Detection of cellulase and xylanase activity in isoelectric-focused gels using agar substrate gels supported on plastic films. Can. J. Microbiol 1984; 30: 1522-5.

6. Mikán JF, Castellanos D. Screening para el aislamiento y caracterización de microorganismos y enzimas parcialmente útiles para la degradación de celulosas y hemicelulosas. Revista Colombiana de Biotecnología. 2004; 6 (1): 58-71.

7. Simonet JE. Recomendaciones para la edificación de Archivos. Archivo General de la Nación. Sistema Nacional de Archivos; 1996. $58 \mathrm{p}$.

8. Singh A, Hayashi K. Microbial Cellulases: protein architecture, molecular properties, and biosynthesis. Advances in Applied Microbiology 1995; 40: 1-44.
9. Kluepfel D. Screning of prokaryotes for cellulose and hemicellulose degrading enzymes. Methods in Enzymology 1988; 160: 180-7.

10. Stoschek CM. Increased uniformity in the response of the Coomasie Blue $\mathrm{G}$ protein assay to different proteins. Analytical Biochemistry 1990; 184:111-16

11. Sunna A, Antrainikian G. Xilanolitic enzymes from fungi and bacteria. Critical Reviews in Biotechnology 1997; 17 (1): 3967.

12. Vaillant M. Microbiología aplicada a la restauración de bienes muebles. Bogotá; Universidad Externado de Colombia: 1999. $43 \mathrm{p}$.

13. Williams ST. Streptomyces in Biodeterioration-their relevance, detection and identification. International Biodeterioration and Biodegradation 1985; 21: 201-9.

Correspondencia: revistanova@unicolmayor.edu.co 